\title{
Lower Extremity Ulcer
}

National Cancer Institute

\section{Source}

National Cancer Institute. Lower Extremity UIcer. NCI Thesaurus. Code C34765.

A circumscribed, inflammatory, and often suppurating lesion that causes necrosis of tissue on the skin of the limb comprising the hip, thigh, leg and foot. 